\title{
What are the Risk Factors for Antisocial Behavior Among Low-income Youth in CapeTown?
}

Frances Gardner ${ }^{1}$, Rebecca Waller ${ }^{1,2}$, Barbara Maughan ${ }^{3}$, Lucie Cluver $^{4}$ and Mark Boyes ${ }^{5}$

${ }^{1}$ Centre for Evidence-Based Intervention, Department of Social Policy and Intervention, University of Oxford

${ }^{2}$ University of Michigan, Department of Psychology

${ }^{3}$ MRC Social Genetic \& Developmental Psychiatry Centre, King's College, London

${ }^{4}$ Centre for Evidence-Based Intervention, Department of Social Policy and Intervention, University of Oxford \& Department of Psychiatry \& Mental Health, University of Cape Town

${ }^{5}$ School of Psychology \& Speech Pathology, Curtin University, Australia

\begin{abstract}
Research in high-income countries has identified an array of risk factors for youth antisocial behavior. However, in low- and middle-income countries, despite higher prevalence of offending and antisocial behavior, there is a paucity of prospective, longitudinal evidence examining predictors. South Africa is a middle-income country with high rates of violence and crime, and a unique social context, characterized by striking income and gender inequality, and increasing number of children orphaned by AIDS. We tested predictors of antisocial behavior at community, family, and individual levels over four years. One thousand and twenty five adolescents from poor, urban South African settlements were assessed in 2005 (50 percent female; $M=13.4$ years) and followed up in 2009. The sample analyzed consisted of the 723 youth (71 percent) assessed at both time points. We employed sociodemographic questionnaires and standardized scales. Validity of our antisocial behavior measure was supported by cross-sectional associations with well-evidenced concomitants of youth antisocial behavior, including drug taking and truancy. Regression analysis indicated that male gender and experience of community violence, but not poverty or abuse, predicted antisocial behavior. Despite many South This research was conducted with grants from the Nuffield Foundation to Gardner \& Cluver, and the John Fell OUP Fund, to Gardner.

Correspondence should be addressed to Frances Gardner, Centre for Evidence-Based Intervention, Department of Social Policy \& Intervention, University of Oxford, 32 Wellington Square, Oxford OX12ER, UK. Email: frances.gardner@spi.ox.ac.uk
\end{abstract}


African youth experiencing abuse and poverty at the family level, our findings suggest that high levels of violence in communities may be a more important factor contributing to the development of antisocial behavior, particularly among males.

Keywords: antisocial behavior; community; HIV/AIDS; orphans; risk factors; violence

\section{Introduction}

Decades of research from longitudinal studies has documented a set of risk factors for antisocial and aggressive behavior at individual (e.g., gender, early-onset conduct problems), family (e.g., harsh or punitive parenting practices; parental violence; poverty), and community levels (e.g., living in a neighborhood with high crime or a gang culture) (Loeber, Farrington, Stouthamer-Loeber, \& Van Kammen, 1998; Murray \& Farrington, 2010). Given the high cost of antisocial behavior to societies (Scott, Knapp, Henderson, \& Maughan, 2001), developing well-evidenced etiological theories and identifying malleable intervention targets remain key research priorities. Indeed, evidence from intervention studies suggests that targeting family- and social-level risk factors reduces the likelihood of children developing antisocial or delinquent behaviors (e.g., Farrington \& Welsh, 2007; Knerr, Gardner, \& Cluver, 2013; Piquero, Farrington, Welsh, Tremblay, \& Jennings, 2009). Nevertheless, the majority of longitudinal research of this topic comes from high-income countries (HIC), and, despite much higher levels of crime and violence in many low- and middle-income countries (LMICs; Krug, Dahlberg, Mercy, Zwi, \& Lozano, 2002), very much less is known about the causes of and prevention possibilities for antisocial behavior in LMICs (Knerr et al., 2013; Murray, Anselmi, Gallo, Fleitlich-Bilyk, \& Bordin, 2013).

\section{Overview of the South African Context}

South Africa is a middle income country with homicide, violent crime, intimate partner violence, and child abuse rates well above those of comparable other countries (Seedat, Van Niekerk, Jewkes, Suffla, \& Ratele, 2009). Of more concern is that, in common with many other countries, youth aged 12-22 years are the most likely perpetrators of violent or aggressive crime. Indeed, approximately 35 percent of the prison population is under 25-year-old (Clark, 2012; Department of Correctional Services, 2010). It is somewhat surprising therefore that, to date, no prospective longitudinal studies have empirically tested the individual-, family-, and social-level risk factors associated with the development of antisocial and violent behavior in youth.

First, the question of whether the same causal factors reliably identified by prospective, longitudinal studies in HIC also predict antisocial behavior in youth samples in South Africa needs to be investigated. It should be noted, however, that some of the factors that might be perceived as contributing to risk in a HIC-context (e.g., low income or bereavement) are relatively normative for many South African youth and thus it is possible that they may not be associated with risk for antisocial behavior in the same way. Conversely, these factors may equally serve to enhance the level of risk in communities (van der Merwe, Dawes, \& Ward, 2012). Indeed, there may be risk factors unique to South Africa's history and the contexts in which young people are growing up, that represent important root causes for antisocial and violent behavior, including societal acceptance of gender violence; historic patterns 
of family disruption due to migration, and family and community violence related to patterns of alcohol abuse (van der Merwe et al., 2012). Surveys and qualitative investigations that have been carried out in recent years among youth in Cape Town (e.g., Burton, 2006; Leoschut, 2009; Leoschut \& Bonora, 2007) have generated hypotheses about a number of inter-related risk and protective factors that may be causally related to the development of antisocial behavior (van der Merwe et al., 2012). These can be conceptualized within an ecological framework (Bronfenbrenner, 1979) operating at societal, community, family, and individual levels, with much of the literature (e.g., van der Merwe et al., 2012), tending to assume that key risk factors are likely to be similar to those known to be common to other societies (Murray \& Farrington, 2010), but with additional contextual factors such as extreme poverty and family disruption, related to historic patterns of oppression, and more recently to high levels of HIV/AIDS infection and death.

\section{Poverty, Income Inequality, and Unemployment}

First, widespread poverty, unemployment, and income inequality have been argued to strongly undermine the social dynamic in South Africa. For example, 70 percent of the population in South Africa is categorized as poor, 48 percent of the population aged 15-25 years was unemployed in 2009 (Presidency of the Republic of South Africa, 2009). Income inequality, indexed by the Gini coefficient, is among the highest in the world. Anger and frustration at lack of opportunity and desire to gain material goods and status is hypothesized to increase the risk for antisocial behavior and crime. Nevertheless, there are many countries in the world with poverty levels comparable to those of South Africa, but without the high levels of violence. As such, it may be that it is the combination of poverty and unemployment with income inequality that contributes to high levels of antisocial behavior. Indeed, in one study of 63 countries (Wood, 2006), South Africa was found to have both the highest levels of homicide and income inequality. Other studies have reported high correlations between country-level inequality and various health outcomes, including violence (Wilkinson \& Pickett, 2009) and family violence (Lansford \& Deater-Deckard, 2012), although the robustness of these associations is unclear (Lynch et al., 2001).

\section{Violence in Communities and Schools}

Second, a more proximate cause for antisocial behavior in South Africa is hypothesized to be the frequent exposure of children to violence and crime in their homes, schools, and communities. For example, in the National Youth Victimization Study (Burton, 2006), 12 percent of youth reported witnessing violent interpersonal disputes between family members, around half of which involved the use of a weapon. In addition, 50 percent of youth reported knowing individuals in their community who had committed crimes, including dealing, mugging or assaulting others. Youth are also victims of violence on a daily basis. For example, in the National Youth Life-style Survey, 52 percent of youth reported being hit, spanked, or caned at school (Leoschut, 2009).

At a community level, violent crime rates in Cape Town are significantly higher than those of high-crime cities in HIC. For example, homicide rates in Cape Town approach double those of Detroit. There also appears to be a disproportionate level of community violence among youth. For example, young people aged 15-34-year- 
old account for over 90 percent of deaths due to homicide (Prinsloo, 2007). Related to the high levels of violence in communities, is a long tradition of male superiority in South Africa, manifested through high levels of violence and sexual violence against women (Jewkes et al., 2006), carrying of weapons, and high readiness to resort to violence to resolve disputes (see Cooper \& Foster, 2008; Jewkes et al., 2006; Seedat et al., 2009). Gang-inspired masculinities are argued to be one of few options to achieve a positive identity and status for males growing up in deprived, marginalized, and violent communities (Bruce, 2007; Cooper \& Foster, 2008). Across a range of societies, large scale studies consistently find higher rates of antisocial behavior among males compared to females (Moffitt, 2001). Given the social context of South Africa, it might be expected that gender differences in antisocial behavior would be particularly pronounced (Seedat et al., 2009).

Empirical research in South Africa has tended to focus on whether violence exposure impacts on the internalizing problems of youth, including post-traumatic stress symptoms and psychological distress (e.g., Shields, Nadasen, \& Pierce, 2008; Ward, Flisher, Zissis, Muller, \& Lombard, 2001). However, aside from risk of early death, and development of internalizing problems, experience of violence is also likely to contribute to the development of antisocial behavior among youth (Burton, 2006), although we are only aware of two studies carried out in LMIC that have tested this question empirically. First, Barbarin, Richter, \& deWet (2001) found that experience of family and community violence was cross-sectionally associated with increased levels of child aggression (aged six-year-old; $\mathrm{N}=625$ ), and this effect was partly mediated through mothers' distress. Second, a recent study in a large, nationally representative sample of youth in South Africa (different from the sample in the current study), we found that community violence predicted increases in youth antisocial behavior over one-year follow-up (Waller, Gardner, \& Cluver, 2014).

\section{Family-Level Risk Factors}

Third, the familial environment of youth growing up in South Africa is also argued to increase likelihood of antisocial behavior developing. In HIC, research has consistently highlighted the importance of stable family structures and particular parenting styles and practices to the development of antisocial behavior, including harsh and rejecting parenting practices (Gershoff, Lansford, Sexton, Davis-Kean, \& Sameroff, 2012; Shaw, Gilliom, Ingoldsby, \& Nagin, 2003), lack of positive parenting (Gardner, Burton, \& Klimes, 2006) and poor parental supervision (Loeber, et al., 1998). In South Africa, it is rarer for children to grow up in a home with both biological parents; family structures and accepted norms for childrearing practice, therefore, differ considerably from those in many HIC (Coovadia, Jewkes, Barron, Sanders, \& McIntyre, 2009). In combination with high rates of poverty, frequent migration between rural areas and cities, and children being orphaned, these family patterns may put children at higher risk of neglect, abuse, and sexual violence, increasing their risk for poor mental health outcomes, including antisocial behavior.

\section{The Impact of HIV/AIDS}

Finally, South Africa is currently experiencing one of the world's most severe HIV/ AIDS epidemics, with 30 percent of pregnant women HIV-positive, and an 


\section{2}

Frances Gardner, Rebecca Waller, Barbara Maughan et al.

estimated 1.9 million children AIDS-orphaned in 2010 (UNAIDS, 2010), predicted to rise to 2.3, million by 2020 (Actuarial Society of South Africa, 2005). AIDSorphaned children experience high levels of internalizing problems, including depression, anxiety, and Post-traumatic Stress Syndrom (PTSD) symptoms, which persist over time (e.g., Bhargava, 2005; Cluver, Gardner, \& Operario, 2007; Cluver, Orkin, Gardner, \& Boyes, 2012; Nyamukapa et al., 2008). Furthermore, the poor mental health outcomes of this group appear to be further compounded by poverty, stigma, physical and emotional abuse, and bullying victimization (e.g., Boyes \& Cluver, 2013; Cluver \& Orkin, 2009; Cluver et al., 2013; Maughan-Brown, 2010). Interestingly, there has also been speculation that children orphaned by AIDS are more likely to develop antisocial behavior, with one writer going as far as to argue that, 'this growing pool of orphans will be at greater than average risk to engage in criminal activity' (Schönteich, 1999). Despite claims of this nature, no studies have empirically tested whether AIDS-orphanhood is prospectively related to developing antisocial or criminal behavior.

\section{Current Study}

The current study examines risk factors associated with the development of antisocial and violent behavior among low-income youth from Cape Town. Using longitudinal data from 2005-2009, the study aimed to test risk factors at the individual, family, and community level. First, we attempted to validate the measure of severe youth antisocial behavior in this context, by examining concurrent associations at time 2 between antisocial behavior scores and other youth risk behaviors, such as risky sex, taking drugs, being drunk, and missing school. Second, predictors of antisocial behavior over time were examined. Hypothesized risk factors were either, (a) well-evidenced factors from studies examining the development of antisocial behavior in HIC, or (b) factors unique to the South African context that have been hypothesized to relate to the high levels of antisocial behavior documented at the population level (Seedat et al., 2009; Ward, van der Merwe, \& Dawes, 2012). Factors were tested at community, family and individual level, at time 1, including age, gender, AIDS-orphaned status, poverty, abuse, exposure to violence in family, and community. Given the paucity of empirical evidence from studies examining risk factors for antisocial behavior among this population, the analysis was exploratory.

\section{Methods}

\section{Participants}

In 2005, 1025 young people were interviewed in Xhosa speaking peri-urban settlements around Cape Town. Sampling included household door-to-door visits in 10 settlements, 9 schools, 18 community organizations, and additional purposive recruitment of street-children and child-headed households, aiming to include these important groups who are often excluded from surveys. Four-year longitudinal follow-up in 2009 achieved retention of 723 children (71 percent). Follow-up challenges included high mobility among the sample - many lived in informal settlements with no administrative systems; demolition of one informal settlement from which 189 children had been recruited in 2005; and near-impossibility of tracing street children due to high mobility and mortality. Twelve interviews were curtailed due to substance inebriation of young people, or police raids. Thirty children at 
follow-up were interviewed in other, rural provinces, and three in prison. Less than 2 percent refused to participate (see Cluver, Orkin, Gardner, \& Boyes 2012, for further information on sampling).

\section{Procedure}

Ethical protocols were approved in 2005 and 2009 by Oxford University and Western Cape Education Department. Participation was voluntary and informed consent was obtained from all children and caregivers. Response rate was 99.7 percent in 2005 and 98.3 percent of those traced in 2009. All data were obtained from young people, who completed a 60-min self-report questionnaire, assisted by interviewers, who were Xhosa-speaking social workers or community health workers. No incentives were provided, although children received refreshments and certificates. Confidentiality was maintained, except if children were at risk of harm or requested assistance.

\section{Measures}

Sociodemographic Information (Time 1). Variables included youth age, gender, ethnicity, household composition, internal migration (to/from Cape Town), living in formal vs. informal housing (informal defined as shack in a backyard or on its own plot), and orphanhood status, including orphanhood due to HIV/AIDS. The UN definition of orphanhood was used - that is, loss of one or both parents among children up to age 18 (Skinner et al., 2006; UNAIDS, 2004); 425 children were AIDS-orphaned, 241 other-orphaned, and 278 non-orphaned. Eighty-one were excluded from analyses due to orphanhood by unknown causes (Cluver, Gardner, \& Operario, 2007, for full definition). Sociodemographic variables were treated as categorical variables, apart from youth age; outcome and risk variables (below) were all treated as continuous variables.

Antisocial Behavior Outcome at Time 2. Antisocial behavior was assessed using a summed composite scale comprising items from the 11-item delinquency subscale of the Youth Self-Report (CBCL-YSR; Achenbach \& Rescorla, 2001), and the 5-item conduct problems subscale of the strengths and difficulties questionnaire (Goodman, 1997). Three antisocial behavior items, adapted from the South African National Primary Schools Violence Survey (Burton, 2008) were added to the questionnaire, asking about carrying a knife or gun for protection, and gang membership. To increase the likelihood that the antisocial behavior items would be considered severe in any cultural context, we selected from this item-pool seven 'severe' items, including Child Behaviour Checklist (CBCL), 'vandalism'; strengths and difficulties questionnaire, 'fights', 'lies or cheats', and 'steals'; additional items, 'carries gun', 'carries knife', and 'member of a gang'. The seven severe items were subjected to Confirmatory Factor Analysis in Mplus 6.0 (Muthen \& Muthen, 2010) with WLSMV estimation. Fit statistics were satisfactory $(\mathrm{CFI}=.99$; TLI $=.99$; $\mathrm{RMSEA}=.015)$ and scale reliability was moderately high $(\alpha=.63)$. A composite score was created by summing the seven items, and this 'antisocial behavior score' was used as the main outcome in all analyses. As a further check on the severe items, all subsequent analyses were also re-run with the full item pool, that is, including the following, do not feel guilty, have bad companions, prefer older kids, run away, truant, swear, use alcohol or drugs, get angry, and lose temper. The pattern of results was unchanged. Other risky behaviors, including drug and alcohol use, and sexual risk behavior, were measured at time 2, using items from the National Survey of HIV and Risk Behavior (Pettifor et al., 2004). 


\section{Frances Gardner, Rebecca Waller, Barbara Maughan et al.}

Hypothesized Risk Variables (Assessed at Time 1). Potential risk and protective variables were identified through literature examining antisocial behavior among samples of youth in low/middle-income, as well as high income countries. Individual level factors included age and gender, and time 1 level of delinquency, measured by the Youth Self Report. Family-level risk factors were assessed as detailed below. For all indices, higher scores represent higher levels of risk:

Poverty. An index was created by summing the following: (i) child hunger, based on a cut-off score of two or more days a week for two separate scales from the South African National Food Consumption Survey (Labadarios et al., 2003) assessing (i) hunger and insufficient food at household level (youth were asked on how many days this week they (a) went to bed hungry; and (b) did not have enough food in the home), (ii) lack of any employment in the household; (iii) receipt of means tested social grants.

Child Abuse. An index was created by summing the responses of youth about whether they experienced physical, emotional, or sexual abuse, using UNICEF scales for sub-Saharan Africa, using conservative cut-offs for severe abuse (Cluver, Orkin, Boyes, Gardner, \& Meinck, 2011; Snider \& Dawes, 2006): (i) Physical abuse was weekly or more frequent beating with an object or deliberate harm; (ii) Emotional abuse was weekly or more frequent exposure to verbal abuse, threats to evict children from home, or invoking evil spirits against children; (iii) Sexual abuse was unwanted genital contact or rape.

Home Violence. A summed score was used that assessed frequency of exposure to past-week verbal violence and physical violence between adults in the household.

Community Level Violence. This was assessed using four items from the Child Exposure to Community Violence Checklist (Richters \& Martinez, 1993), adapted to reflect commonest community traumas for youth in South Africa, as identified by national police statistics (SAPS, 2004). The index was created by summing the responses of youth about whether they had, (a) witnessed someone being shot; (b) witnessed someone being stabbed; (c) been physically attacked in their community; (d) been robbed in their community.

\section{Analytic Strategy}

Data were analyzed using SPSS (v19.0). First, as a preliminary check, differences in baseline sociodemographic characteristics of children retained and lost to followup were noted using Chi-squared tests and one-way Analysis of variances (ANOVAs). Second, the validity of the main outcome measure, time 2 antisocial behavior score was examined. A series of one-way ANOVAs were run to examine cross-sectional associations between youth antisocial score and concomitants of antisocial behavior, including truancy, drug and alcohol use, and risky sexual behavior. Third, hierarchical multiple regression was used to examine individual-, family-, and community-level risk factors for antisocial behavior. We note that analyses at both time points focus only on the young people $(n=723)$ for whom we had data at both time 1 and time 2 . Nevertheless, we analyze attrition with respect to the 
Table 1. Descriptive Statistics for Main Study Variables (Continuous Measures)

\begin{tabular}{lccccc}
\hline & $\mathrm{N}$ & $M$ & $S D$ & Minimum & Maximum \\
\hline $\begin{array}{l}\text { Outcome (time 2) } \\
\text { Antisocial behavior score }\end{array}$ & 723 & .57 & .93 & 0 & 6 \\
$\begin{array}{l}\text { Risk factors (time 1) } \\
\text { Age }\end{array}$ & 723 & 13.74 & 1.62 & 10 & 19 \\
Delinquency & 723 & 1.62 & 1.68 & 0 & 8 \\
'Child abuse' index & 723 & 1.00 & 1.05 & 0 & 6 \\
'Home poverty' index & 716 & .97 & .95 & 0 & 3 \\
'Community violence' index & 720 & 1.27 & 1.02 & 0 & 4 \\
\hline
\end{tabular}

originally recruited sample of 1025 , in order to comment on generalizability from the sample analyzed to the larger sample recruited.

\section{Results}

\section{Preliminary Data Check}

Prior to analysis, differences between children lost (and thus not included in these analyses) compared to those retained at follow-up were examined. Those lost were more likely to be male $\left(\chi^{2}(1)=4.18, p=.04\right.$; Cramer's phi $\left.(V)=.06\right)$, older $(F(1$, $1022)=17.81, \quad p<.001$; partial $\left.\eta^{2}=.02\right)$, and living in informal housing $\left(\chi^{2}(1)=6.24, p=.01 ; V=.08\right)$, and to show somewhat higher levels of conduct problems, $(F(1,1015)=5.6, p<.02)$. Although follow-up of 71 percent was relatively high after four years for this highly mobile and at-risk population, generalizability of the results should be interpreted in light of the fact that some of the most vulnerable children from our original sample, and potentially those most at risk of developing antisocial behavior, were among those who had died or were unable to be traced, and were not included in the analyses at either time point.

\section{Descriptive Statistics}

Descriptive statistics for continuous study variables are presented in Table 1. Additionally, 49 percent of the sample were female, 39 percent had migrated to/from Cape Town, 72 percent were parentally bereaved, 41 percent had been orphaned specifically by AIDS, and 36 percent lived in an informal dwelling. Partial correlations between continuous main study variables were computed, controlling for gender (Table 2). Variables assessed at time 1 showed small to moderate correlations, including associations between delinquency and the family- and community-level risk indices. Controlling for gender, time 1 delinquency, experience of community violence and age all showed modest correlations with antisocial behavior score at time 2 .

\section{Concomitants of Antisocial Behavior}

Cross-sectional analyses were run, to examine concurrent validity of the antisocial behavior score. Specifically, youth with higher scores at time 2 were more likely to be male $(F(1,722)=17.92, p<.001)$, older $(r=.07, p<.05)$ regularly missing 
Table 2. Partial Correlations Among Main Study Variables, Controlling for Gender

$\begin{array}{lllll}1 & 2 & 3 & 4 & 5\end{array}$

1. Antisocial behavior score time 2

2. Age

3. Delinquency time 1

4. 'Community violence' index time 1

5. 'Child abuse' index time 1

6. 'Home poverty' index time 1

$\begin{array}{ccccc} & .08^{*} & & & \\ & .10^{*} & .25^{* * *} & & \\ \text { x time } 1 & .12^{* *} & .08^{*} & .18^{* * *} & \\ & -.01 & -.09 & .16^{* * *} & .26^{* * *} \\ 1 & .06 \dagger & .27^{* * *} & .36^{* * *} & .09^{*}\end{array}$

.01

$\dagger p<.10 ;{ }^{*} p<.05 ;{ }^{* *} p<.01 ;{ }^{* * *} p<.001$.

school $(F(1,721)=8.83, p<.01)$, to have been drunk $(F(1,583)=26.47$, $p<.001)$, or to have taken drugs at least once in the last month $(F(1,584)=66.52$, $p<.001)$, and there was a trend toward them being more likely to have had sex before the age of $15(F(1,378)=3.01, p<.10)$. Finally, in contrast to Schönteich's (1999) hypothesis, antisocial behavior scores were not associated with being orphaned (from any cause) nor with being orphaned by AIDS at time 2 .

\section{Predictors of Antisocial Behavior}

Hierarchical multiple regression was used to examine predictors of antisocial behavior. In step 1, demographic factors and individual-level covariates were entered (gender, age, migration to/from Cape Town, living in formal vs. informal housing, orphanhood status, and time 1 delinquency). In step 2, the 'home poverty', 'child abuse', and 'community violence' risk indices were entered. Table 3 shows the results from the regression analysis. The overall model was significant, $F(9$, $702)=4.88, p<.001$. Male gender was significantly associated with higher levels of antisocial behavior $(\beta=-.16, p<.001)$. None of the other individual-level or demographic covariates contributed significantly to the model. The inclusion of the family- and community-level risk indices in the second step of the regression explained an additional 1 percent of the variance in antisocial behavior, $\Delta F=2.92$, $p<.05$. The risk index of 'community violence' predicted antisocial behavior $(\beta=.11, p<.01)$, but neither of the family-level risk indices (poverty, abuse) were significant predictors. The pattern of results was the same whether the family- and community-level risk indices were entered simultaneously or in separate models.

\section{Post hoc Moderation Analysis}

The first set of models found a main effect of community violence and gender on antisocial outcomes. Inspection of descriptive data revealed gender differences in both exposure to community violence and antisocial behavior, thus a second, exploratory hierarchical multiple regression was run to examine the moderating effect of gender on the experience of community violence in predicting antisocial behavior. As before, individual-level and demographic factors were controlled for in step 1 . In step 2, the main effect of experiencing community violence was entered. In step 3, the product term was entered: 'experience of community 
Table 3. Regression Analysis Examining the Prediction of Time 2 Antisocial Behavior Score by Time 1 Individual-, Family- and Community-Level Risk Factors

\begin{tabular}{llccc}
\hline Step & Independent variables & $\beta$ & $R^{2}$ & $R^{2} \Delta$ \\
\hline 1. & Gender & $-.16^{* * *}$ & & \\
& Age & .07 & & \\
& Time 1 delinquency & .08 & & \\
Orphan status & .01 & $.05^{* * *}$ & \\
& Migration & -.02 & & \\
2. & .06 & $.066^{* * *}$ & $.01^{*}$ \\
\hline
\end{tabular}

Note that the pattern of findings was unchanged when we log-transformed antisocial behavior scores. Further, we found the same pattern of effects using a fuller 15-item measure of antisocial behavior (see Methods). $\dagger p<.10 ; * p<.05 ; * * p<.01 ; * * * p<.001$.

violence $\times$ gender'. Variables were centered before creating the product term. Significant interaction effects were examined by testing if the slope of the regression lines for males vs. females differed significantly from zero (Cohen, Cohen, West, \& Aiken, 2003). Regression equations were used to plot mean values for antisocial behavior at minimum and maximum values of community violence experience as a function of gender (male vs. female). Table 4 shows the results from the regression analysis. The overall model was significant, $F(8,703)=6.12, p<.001$. As before, there was a main effect of both male gender $(\beta=-.15, p<.001)$ and experience of community violence $(\beta=.18, p<.001)$ in predicting antisocial behavior. The inclusion of the interaction term in the model explained an additional 1 percent in the variance of antisocial behavior, $\Delta F=5.22, p<.05$. There was also a significant unique interaction effect between gender and experience of community violence $(\beta=-.11, p<.05)$. Probing of this significant interaction effect revealed that experience of community violence predicted antisocial behavior score in males $(\beta=.16$, $p<.01$ ) but not females $(\beta=.01, p=.80)$ (see Figure 1 for plots of the simple slopes).

\section{Discussion}

This study examined the development of antisocial behavior in sample of South African youth. In common with other LMIC, there is paucity of prospective, longitudinal evidence examining the development of antisocial behavior in South Africa, although much has been written about the social context and the high rates of violence and crime at a population level (Clark, 2012; Burton, 2006; Leoschut, 2009; Seedat et al., 2009; Ward et al., 2012). The current study is the first, to our knowledge, to adopt a prospective, longitudinal design to empirically test the prediction of antisocial behavior by individual-, family-, and community-level risk factors among a low-income, sample of adolescents in Africa. 
808 Frances Gardner, Rebecca Waller, Barbara Maughan et al.

Table 4. Regression Analysis Testing for Moderation by Gender on the Prediction of Antisocial Behavior Score at Time 2 by Experience of Community Violence at Time 1

\begin{tabular}{|c|c|c|c|c|}
\hline Step & Independent variables & $\beta$ & $R^{2}$ & $R^{2} \Delta$ \\
\hline \multirow[t]{6}{*}{1.} & Gender & $-.15 * * *$ & & \\
\hline & Age & .06 & & \\
\hline & Time 1 delinquency & -.01 & & \\
\hline & Orphan status & .01 & & \\
\hline & Migration & .07 & & \\
\hline & Household type & .06 & $.05 * * *$ & \\
\hline 2. & Community violence & $.18 * * *$ & $.06 * * *$ & $.01 * *$ \\
\hline 3. & Community violence $\times$ gender & $-.11 *$ & $.07 * * *$ & $.01 * *$ \\
\hline
\end{tabular}

$\dagger p<.10 ; * p<.05 ; * * p<.01 ; * * * p<.001$.

\section{Male Gender and Antisocial Behavior Scores}

First, the results support well-documented findings suggesting that antisocial and violent, behavior among South African youth is largely perpetrated by males, albeit a small minority of males in this sample. Male gender was strongly crosssectionally associated with antisocial behavior and predicted higher scores at fouryear follow-up. Some literature focused on the South African context links violence to conceptualizations of masculinity, influenced by a patriarchal ideology and gang culture (Foster, 2012; Seedat et al., 2009). These findings arguably support the need for current discourses about masculinity in South Africa to be challenged. One solution to youth violence is argued to involve a 'process of human development'

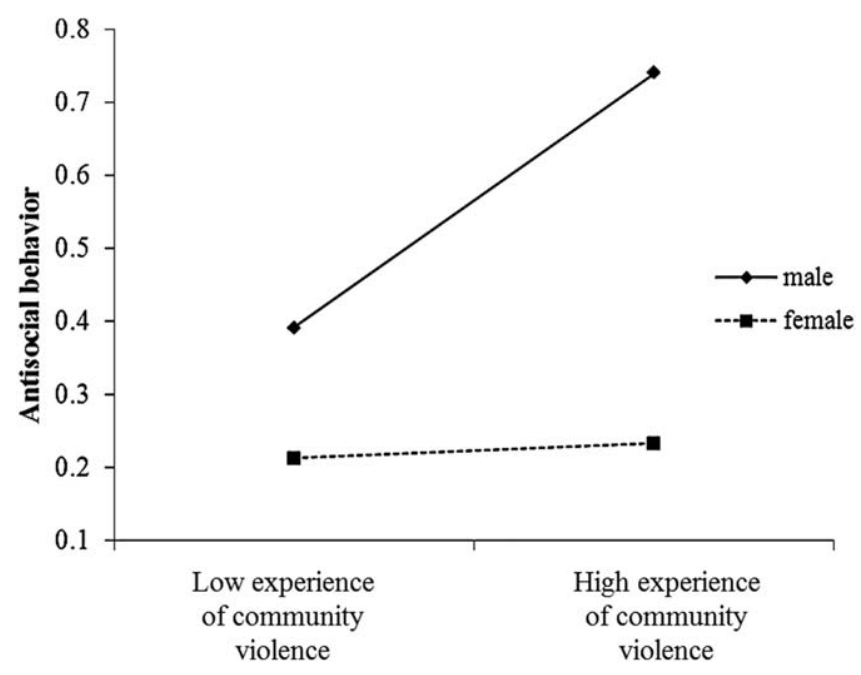

Figure 1. Simple slopes showing experience of community violence predicting antisocial behavior score in males versus females. 
(Simpson, 2001), which gives young males in particular, a stake in communities that does not involve antisocial or violent behavior.

\section{Experience of Community Violence}

Second, antisocial behavior was predicted by exposure to community-level violence controlling for earlier delinquency and sociodemographic covariates (including gender, age, migration, and orphanhood). The community violence index included youth witnessing shootings, stabbings, being attacked, and being robbed. Given the well-documented high levels of violence exposure for youth in South Africa, it is interesting that this index of community violence still predicted antisocial behavior development over four years, even after controlling for earlier delinquency, gender, and age. The results fit with the Center for Justice and Crime Prevention's survey of youth resilience to crime, where 70 percent of non-offenders reported being exposed to community violence, compared to 90 percent of respondents within an offender subgroup (Burton, Leoschut, \& Bonoro, 2009). In addition to this main effect, our post hoc analysis revealed an interaction with gender, such that this main effect of community violence on antisocial behavior is carried almost entirely by males.

Specifically, exposure to community violence at time 1 predicted higher antisocial behavior only among males. This finding highlights again the particular risk for males to develop antisocial behavior. It is unclear from the current study however, whether males are particularly vulnerable to the effects of community violence, or simply more likely to be exposed to it. High exposure for some young people will be a random event, but for others it may result from association with peer and gangs who engage in violence or other offending. Nevertheless, finding ways to challenge these processes seems an important step in reducing the transmission of violence from adult to young males within communities.

\section{Other Family-Level Risk Factors}

Third, somewhat surprisingly, neither of the family-level risk indices predicted antisocial behavior development. In studies from HIC, child maltreatment and abuse are well-documented risk factors for the development of conduct problems (Dodge \& Pettit, 1993). In the current study, the 'child abuse' index, which assessed children's cumulative experience of physical, verbal and sexual abuse, and witnessing domestic violence, was not a risk factor for later antisocial behavior. Nevertheless, this index was cross-sectionally associated with delinquency, and it may be that the follow-up period of four years was not able to detect significant longitudinal effects of family-level abuse on the development of antisocial behavior. In case the link between abuse and antisocial behavior might depend on the type of abuse reported, we conducted further regression analyses with each abuse type in a separate model; although abuse was associated with severe conduct problems at time 1, no type of abuse was predictive of antisocial behavior four years later. There are several possible explanations for this lack of association over time. Firstly, by time 2, when many young people were approaching older adolescence, it may be that the effects of abuse in the family are relatively less important than other variables such as peer and community influence. Secondly, it is possible that despite our definitions of abuse including only severe levels of abuse, that some of these forms of (e.g.) 
hitting in the family are considered normative in some contexts (Gershoff et al., 2012), and therefore were not predictive of severe antisocial behavior over time.

The 'home poverty' index also did not predict antisocial behavior. It is difficult to draw conclusions about this finding, however, given the low-income sample being assessed. The three-item index may not have been able to adequately differentiate between different experiences of poverty within the sample, especially given the fact that all families in the sample were living in high-deprivation areas. As there may be limitations in the use of a means tested 'grant receipt' as part of a poverty index, we re-ran the regressions with each poverty measure entered separately; the results were unchanged. Alternatively, it may be that family-level variations in poverty, at this high level of deprivation, are not associated with antisocial behavior development, at least in this context, or that the experience of stark social inequalities may be a more salient influence. It is worth noting that this finding differs from the conclusions of a recent systematic review of (mainly cross-sectional) data from another highly unequal, middle income country, Brazil (Murray et al., 2013), although these studies differed from the present study, in sampling a wider range of income levels.

\section{Family HIV/AIDS}

Finally, it is also worth noting that orphanhood by AIDS was not associated with antisocial behavior (neither cross-sectionally nor longitudinally). This finding is interesting given that it has previously been argued that parental death from HIV/ AIDS will put a generation of youth at risk of criminality (Schönteich, 1999). In addition, previous longitudinal analyses with the same sample indicate that being orphaned by AIDS is strongly predictive of worsening levels of depression, anxiety and post-traumatic stress disorder over time, controlling for age, gender, baseline mental health, and sociodemographic covariates (Cluver, Orkin, Gardner, \& Boyes 2012). It therefore appears that although AIDS-orphanhood is a risk factor for poor mental health outcomes, the risk may be limited to internalizing problems, and that alternative factors in the ecology of youth are more important to the development of externalizing problems.

\section{Limitations of the Current Study}

This study has a number of limitations. First, although strenuous attempts were made to find participants after four years, 295 children were not traceable or had died. Analysis of the 2005 data suggests that those lost to follow-up were more vulnerable. However, as these 'lost' young people were not included in the analysis, the main implication for interpretation of the results is that the findings may not be generalizable to the slightly older, more troubled and impoverished sample originally recruited, and that, potentially, this may underestimate strength of predictors of antisocial behavior. Second, the data were entirely self-reported and youth may not have been truthful in their responses. To try and minimize social desirability effects, antisocial and sexual behavior items appeared on a clearly marked 'confidential' section of the questionnaire, which was subsequently removed from the main questionnaire and placed in an unmarked envelop in front of participants. Nevertheless, the low base rate of youth endorsing items, such as carrying a gun or knife, relative to responses of youth on other surveys (e.g., Leoschut, 2009) is 
puzzling, and suggests that antisocial behavior scores in the current sample may have been an underestimate, reducing the likelihood of obtaining significant effects for predictor variables. Furthermore, our efforts to provide data to support the validity of the antisocial behavior score were limited in utilizing analyses of the present sample. Limitations in the measure of poverty were outlined earlier. Third, although male gender and experience of community violence both predicted later antisocial behavior, the amount of variance explained by models was quite small (between 5 and 7 percent). While the four-year follow up period may explain the small amount of variance explained, other unmeasured factors may contribute to the risk for developing antisocial behavior. For example, qualitative investigations have highlighted perceived income disparity, gang culture, and a lack of parental involvement as salient risk factors for youth engagement in criminality (Leoschut \& Bonora, 2007). Unfortunately, measures of these variables were not available in our data, but future empirical studies are needed to examine their prediction of youth antisocial behavior.

\section{Conclusions and Future Directions}

Despite these limitations, there are a number of strengths to the study. It is one of the first empirical studies to prospectively examine risk factors for antisocial behavior among a large, low-income sample of African youth, a population wellrecognized for being at risk of developing severe forms of violent, criminal, and gang-related behavior. In addition, the oversampling of child-headed households, non-school attending children, and children orphaned by HIV/AIDS potentially increases the generalizability of the findings, and enables stronger conclusions to be drawn about risk processes for antisocial behavior among this population. Young people growing up in post-apartheid South Africa experience marginalization, impoverishment, and striking levels of relative deprivation (Foster, 2012), and rates of antisocial, violent, and criminal behavior are an increasingly concerning social problem (Clark, 2012). This study suggests that experience of community violence exacerbates the likelihood of developing high levels of antisocial behavior, in particular, for young men. At the same time, future empirical studies are needed to explore further the unexpected failure to find any association between experience of abuse and youth antisocial behavior, and to examine the role of family-level risk and protective factors in its development during childhood and adolescence.

\section{References}

Achenbach, T., \& Rescorla, L. (2001). Manual for the ASEBA school-age forms and profiles. Burlington, VT: University of Vermont.

Actuarial Society of South Africa. (2005). ASSA2003: AIDS and demographic model. Cape Town, South Africa: ASSA.

Barbarin, O., Richter, L., \& deWet, T. (2001). Exposure to violence, coping resources, and psychological adjustment of South African children. American Journal of Orthopsychiatry, $71,16-25$.

Bhargava, A. (2005). AIDS epidemic and the psychological well-being and school participation of Ethiopian orphans. Psychology, Health and Medicine, 10, 263-275.

Boyes, M., \& Cluver, L. (2013). Relationships among HIV/AIDS orphanhood, stigma, and symptoms of anxiety and depression in South African youth: A longitudinal investigation using a path analysis framework. Clinical Psychological Science, 1, 321-330.

Bronfenbrenner, U. (1979). The ecology of human development: Experiments by nature and design. Cambridge, MA: Harvard University Press. 


\section{Frances Gardner, Rebecca Waller, Barbara Maughan et al.}

Bruce, D. (2007). To be someone: Status insecurity and violence and South Africa. In P. Burton (Ed.), Someone stole my smile: An exploration into the causes of youth violence in South Africa (pp. 57-69). Cape Town: Center for Justice and Crime Prevention.

Burton, P. (2006). Snapshot results of the 2005 national youth victimisation study. CJCP research bulletin, 1. Claremont, South Africa: Centre for Justice and Crime Prevention.

Burton, P. (2008). Merchants, skollies and stones: Experiences of school violence in South Africa. Monograph series, No. 4. Cape Town: Centre for Justice and Crime Prevention.

Burton, P., Leoschut, L., \& Bonora, A. (2009). Walking the tightrope: Youth resilience to crime in South Africa. Claremont, South Africa: Center for Justice and Crime Prevention.

Clark, J. N. (2012). Youth violence in South Africa: The case for a restorative justice response. Contemporary Justice Review: Issues in Criminal, Social and Restorative Justice, $15,77-95$.

Cluver, L., Gardner, F., \& Operario, D. (2007). Psychological distress amongst AIDSorphaned children in urban South Africa. Journal of Child Psychology \& Psychiatry, 48, $755-763$.

Cluver, L., \& Orkin, M. (2009). Stigma, bullying, poverty and AIDS-orphanhood: Interactions mediating psychological problems for children in South Africa. Social Science and Medicine, 69, 1186-1193.

Cluver, L., Orkin, M., Boyes, M. E., Gardner, F., \& Meinck, F. (2011). Transactional sex amongst AIDS-orphaned and AIDS-affected adolescents predicted by abuse and extreme poverty. Journal of Acquired Immune Deficiency Syndromes, 58, 336-343.

Cluver, L., Orkin, M., Boyes, M. E., Sherr, L., Makasi, D., \& Nikelo, J. (2013). Pathways from parental AIDS to child psychological, educational, and sexual risk: Developing an empirically-based interactive theoretical model. Social Science \& Medicine, 87, 185-193.

Cluver, L. D., Orkin, M., Gardner, F., \& Boyes, M. E. (2012), Persisting mental health problems among AIDS-orphaned children in South Africa. Journal of Child Psychology and Psychiatry, 53, 363-370.

Cohen, J., Cohen, P., West, S., \& Aiken, L. (2003). Applied multiple regression/correlation analysis for the behavioral sciences. Mahwah, NJ: Lawrence Erlbaum.

Cooper, A., \& Foster, D. (2008). Democracy's children? Masculinities of adolescents awaiting trial. Thymos: Journal of Boyhood Studies, 2, 3-25.

Coovadia, H., Jewkes, R., Barron, P., Sanders, D., \& McIntyre, D. (2009). The health and health system of South Africa: Historical roots of current public health challenges. Lancet, $374,817-834$.

Department of Correctional Services. (2010). Statistics on incarceration levels in South Africa as on the last day of May 2010. Retrieved July 31, 2012, from http://www.dcs. gov.za/AboutUs/StatisticalInformation.aspx

Dodge, K. A., \& Pettit, G. S. (2003). A biopsychosocial model of the development of chronic conduct problems in adolescence. Developmental Psychology, 39, 349-359.

Farrington, D. P., \& Welsh, B. C. (2007). Saving children from a life of crime: Early risk factors and effective interventions. Oxford: OUP.

Foster, D. (2012). Gender, class, race and violence. In C. Ward, A. van der Merwe, \& A. Dawes (Eds.), Youth violence: Sources and solutions in South Africa. Cape Town, South Africa: UCT Press.

Gardner, F., Burton, J., \& Klimes, I. (2006). Randomised controlled trial of a parenting intervention in the voluntary sector for reducing child conduct problems: Outcomes and mechanisms of change. Journal of Child Psychology \& Psychiatry, 47, 1123-1132.

Gershoff, E., Lansford, J., Sexton, H., Davis-Kean, P., \& Sameroff, A. (2012). Longitudinal links between spanking and children's externalizing behaviors in a national sample of white, black, Hispanic, and Asian American families. Child Development, 83, 838-843.

Goodman, R. (1997). The strengths and difficulties questionnaire: A research note. Journal of Child Psychology \& Psychiatry, 38, 581-586.

Jewkes, R., Dunkle, K., Koss, M. P., Levin, J. B., Nduna, M., Jama, N., et al. (2006). Rape perpetration by young, rural South African men: Prevalence, patterns and risk factors. Social Science \& Medicine, 63, 2949-2961.

Knerr, W., Gardner, F., \& Cluver, L. (2013). Improving positive parenting skills and reducing harsh and abusive parenting in low- and middle-income countries: A systematic review. Prevention Science, 14, 352-363. 
Krug, E., Dahlberg, L., Mercy, J., Zwi, A., \& Lozano, R. (2002). World report on violence and health. Geneva: World Health Organisation.

Labadarios, D., Maunder, E., Steyn, N., MacIntyre, U., Swart, R., Gericke, G., et al. (2003). National food consumption survey in children aged 1-9 years: South Africa 1999. South African Journal of Clinical Nutrition, 56, 106-109.

Lansford, J. E., \& Deater-Deckard, K. (2012). Childrearing discipline and violence in developing countries. Child Development, 83, 62-75.

Leoschut, L. (2009). Running nowhere fast: Results of the 2008 National Youth Lifestyle Survey. Cape Town: Center for Justice and Crime Prevention.

Leoschut, L., \& Bonora, A. (2007). Offender perspectives on violent crime. In P. Burton (Ed.), Someone stole my smile: An exploration into the causes of youth violence in South Africa (pp. 89-111). Cape Town, South Africa: Center for Justice and Crime Prevention.

Loeber, R., Farrington, D. P., Stouthamer-Loeber, M., \& Van Kammen, W. B. (1998). Antisocial behavior and mental health problems: Explanatory factors in childhood and adolescence. Mahwah, NJ: Lawrence Erlbaum.

Lynch, J., Smith, G. D., Hillemeier, M., Shaw, M., Raghunathan, T., \& Kaplan, G. (2001). Income inequality, the psychosocial environment, and health: Comparisons of wealthy nations. The Lancet, 358, 194-200.

Maughan-Brown, B. (2010). Stigma rises despite antiretroviral roll-out: A longitudinal analysis in South Africa. Social Science \& Medicine, 70, 368-374.

Moffitt, T. E. (Ed.). (2001). Sex differences in antisocial behaviour: Conduct disorder, delinquency, and violence in the Dunedin Longitudinal Study. Cambridge: Cambridge University Press.

Murray, J., Anselmi, L., Gallo, E., Fleitlich-Bilyk, B., \& Bordin, I. A. (2013). Epidemiology of childhood conduct problems in Brazil: Systematic review and meta-analysis. Social Psychiatry and Psychiatric Epidemiology, 48, 1527-1538.

Murray, J., \& Farrington, D. P. (2010). Risk factors for conduct disorder and delinquency: Key findings from longitudinal studies. Canadian Journal of Psychiatry, 55, 633-642.

Muthen, L. K., \& Muthen, B. O. (2010). Mplus user's guide (6th ed.). Los Angeles, CA: Muthen \& Muthen.

Nyamukapa, C., Gregson, S., Lopman, B., Saito, S., Watts, H., Monasch, R., et al. (2008). HIV-associated orphanhood and children's psychosocial distress: Theoretical framework tested with data from Zimbabwe. American Journal of Public Health, 98, 133-141.

Pettifor A., Rees H., Steffenson, A., Hlongwa-Madikizela, L., MacPhail, C., Vermaak, K., et al. (2004). HIV and sexual behavior among young South Africans: A national survey of 15-24 year olds. Johannesburg, South Africa: Reproductive Health Research Unit, University of the Witwatersrand.

Piquero, A. R., Farrington, D. P., Welsh, B. C, Tremblay, R., \& Jennings, W. G. (2009). Effects of early family/parent training programs on antisocial behavior and delinquency. Journal of Experimental Criminology, 5, 83-120.

Presidency of the Republic of South Africa. (2009). Development indicators 2009. Retrieved July 31, 2012, from www.thepresidency.gov.za/learning/me/indicators/2009/indicators.pdf

Prinsloo, M. (Ed.). (2007). A profile of fatal injuries in South Africa: 7th annual report of the NIMSS, 2005. Retrieved July 31, 2012, from http://sahealthinfo.org/violence/ 2005injury.html

Richters, J., \& Martinez, P. (1993). The NIMH Community Violence Project: 1. Children as victims of and witnesses to violence. Psychiatry, 56, 7-21.

SAPS (South African Police Services). (2004). Crime in the Republic of South Africa for the period from April to March 1994/5 to 2003/4. Pretoria, South Africa: Crime Information Analysis Centre.

Schönteich, M. (1999). Age and aids: South Africa's crime time bomb? African Security Studies, 8, 34-44.

Scott, S., Knapp, M., Henderson, J., \& Maughan, B. (2001). Financial cost of social exclusion: Follow up study of antisocial children into adulthood. BMJ, 323, 191-194.

Seedat, M., Van Niekerk, A., Jewkes, R., Suffla, S., \& Ratele, K. (2009). Violence and injuries in South Africa: Prioritising an agenda for prevention. Lancet, 374, 1011-1022.

Shaw, D. S., Gilliom, M., Ingoldsby, E. M., \& Nagin, D. S. (2003). Trajectories leading to school-age conduct problems. Developmental Psychology, 39, 189-193. 


\section{Frances Gardner, Rebecca Waller, Barbara Maughan et al.}

Shields, N., Nadasen, K., \& Pierce, L. (2008). The effects of community violence on children in Cape Town, South Africa. Child Abuse \& Neglect, 32, 589-601.

Simpson, G. (2001). Shock troops and bandits: Youth crime and politics. In J. Steinberg (Ed.), Crime wave (pp. 115-128). Johannesburg, South Africa: Witwatersrand University Press.

Skinner, D., Tsheko, N., Mtero-Munyati, S., Segwabe, M., Chibatamoto, P., Mfecane, S., et al. (2006). Towards a definition of orphaned and vulnerable children. AIDS and Behavior, 10, 619-626.

Snider, L., \& Dawes, A. (2006). Psychosocial vulnerability and resilience measures for national-level monitoring of orphans and other vulnerable children: Recommendations for revision of the UNICEF psychological indicator. Retrieved July 31, 2012, from http:// www.childinfo.org/files/PsychosocialMeasures_Final06.pdf

UNAIDS. (2004). Children on the Brink 2004: A joint report of new orphan estimates and a framework for action. Geneva: UN.

UNAIDS. (2010). Report on the global AIDS epidemic. Geneva: UN.

van der Merwe, A., Dawes, A., \& Ward, C. (2012). The development of youth violence: An ecological understanding. In C. Ward, A. van der Merwe, \& A. Dawes (Eds.), Youth violence: Sources and solutions in South Africa (pp. 53-91). Cape Town, South Africa: UCT Press.

Waller, R., Gardner, F., \& Cluver, L. (2014). Shared and unique predictors of antisocial and substance use behavior among a nationally representative sample of South African youth. Aggression and Violent Behavior, 19, 629-636. doi: 10.1016/j.avb.2014.09.002

Ward, C., Flisher, A., Zissis, C., Muller, M., \& Lombard, C. (2001). Adolescents' exposure to violence: Relationships between exposure and symptoms. Injury Prevention, 7, 297301.

Ward, C., van der Merwe, A., \& Dawes, A. (Eds.). (2012). Youth violence: Sources and solutions in South Africa. Cape Town, South Africa: UCT Press.

Wilkinson, R. G., \& Pickett, K. (2009). The spirit level. London: Allen Lane.

Wood, A. (2006). Correlating violence and socio-economic inequality: An empirical analysis. Retrieved October 15, 2012, from http://www.omct.org/files/interdisciplinary-study/ correlations_report_final_draft_29_05_06.pdf 